\title{
PERCEPÇÃO DOS ESTUDANTES DE PEDAGOGIA NA EDUCAÇÃO INCLUSIVA COMO DISCIPLINA OBRIGATÓRIA NA GRADE CURRICULAR NAS INSTITUIÇÕES DE ENSINO SUPERIOR EM PERNAMBUCO - BRASIL
}

\author{
Lucilene Maria da Costa $^{1}$ \\ Cristiano do Nascimento Siqueira ${ }^{2}$ \\ Cicero Pereira Batista ${ }^{3}$
}

\section{RESUMO}

Com base nas Diretrizes curriculares nacionais que visam à formação do professor atuante na educação dos anos iniciais, determinam que os estabelecimentos de ensino superior incluam, em sua grade curricular, a formação de professores para atender a diversidade, incluindo conhecimento sobre as especificidades dos alunos com necessidades educacionais especiais. Simultaneamente, é sabido que o acesso à escola básica não tem sido contemplado com investimentos necessário para custear as mudanças cabíveis nas diferentes dimensões na formação inicial e continuada dos professores. Este deverá estar preparado ao adentrar em sala de aula e identificar pessoas que apresentam cuidados especiais, como são os casos de alunos com limitações. Diante do exposto, a presente dissertação teve como objetivo divulgar percepção dos estudantes do curso de pedagogia na educação inclusiva e a obrigatoriedade da disciplina na grade curricular em Pernambuco a partir da perspectiva de futuros dos discentes. Para tanto, realizou-se uma pesquisa quantitativa e qualitativa, por meio de questionário, com graduandos no curso de pedagogia do Estado de Pernambuco. Ao todo, participaram da pesquisa 35 estudantes. Foi observado com as respostas diferentes posicionamentos, mas uma concordância dos licenciados a respeito da importância de discutir o tema, principalmente estando em posição de futuros docentes. Os dados revelam aspectos importantes da formação docente para com a educação inclusiva e fornece dados importantes para educação, em geral.

Palavras-chave: Estudantes. Pedagogia. Currículo. Educação inclusiva.

\section{INTRODUÇÃO}

\subsection{Linha de pesquisa}

\section{- Currículo e ensino}

Diante do desejo na superação da dicotomia é que possui o interesse em retomar a argumentação da qualidade de ensino na escola dos anos iniciais, basicamente, seus métodos e conteúdo. Em outros trabalhos, temos 
valiosas contribuições de estudiosos da sociologia que discutir em sua pesquisa o currículo e o ensino. De acordo com Candau (1984):

A importância de conteúdo, métodos e relações para a definição tanto da qualidade como do caráter da prática pedagógica parece, assim, aceita pelos autores da sociologia do currículo. Do mesmo modo, autores associados à Didática têm assinalado o caráter multidimensional do processo de ensino e proposto a articulação dos diversos estruturantes do método didático e a necessária superação de dicotomizações como conteúdo $X$ método, dimensão intelectual $X$ dimensão afetiva, dimensão objetiva $X$ dimensão subjetiva, dimensão lógica X dimensão psicológica etc. (CANDAU, 1984, p. 53).

De acordo com Silvar (2019) pensar o currículo na atualidade implica em reconhecer que as mudanças sociais, estruturais e exigências de profissionais capacitados exercem influências na organização dos currículos, especialmente na Universidade, na qual se constitui em um espaço de aprendizagens e produção de conhecimentos.

Nesse sentido, destaca-se a grande preocupação de refletir como ocorre a formação profissional dos estudantes e como se organiza o currículo para atender estes propósitos.

Existem muitos desafios que envolvem o rompimento com a homogeneização das estruturas curriculares, formação de profissionais, educação escolar, dentre outros. O conteúdo das disciplinas guarda relação com os domínios da cultura, as áreas do conhecimento, as ciências de referência, e sua organização devem refletir a organização das ciências em sua história, em sua ordem lógica e no seu método, sem perder de vista a finalidade de ensino-aprendizagem, ou seja, a dimensão didática do processo pedagógico (SAVIANI, 2010, p. 13).

Vale destacar que, ao reconhecer que cada aluno aprende de uma maneira sendo possível compreender melhor a importância de adaptar o currículo de forma que possa atender às diferentes necessidades de aprendizagem de cada um, possibilitando que todos tenham a oportunidade de aprender. "O currículo deveria ser adaptado às necessidades das crianças, e não vice-versa. Escolas deveriam, portanto, prover oportunidades curriculares 
que sejam apropriadas à criança com habilidades e interesses diferentes" (UNESCO, 1994, s/n).

É notório que a educação é de grande relevância para o desenvolvimento social e econômico de um país. Conseguintemente, esta, é responsável pela inclusão do grupo de menor poder aquisitivo. Logo, uma educação inclusiva se torna cada vez mais necessária em todos os níveis de ensino, principalmente, no meio acadêmico.

\subsection{Tema}

\section{- Educação inclusiva}

A educação inclusiva tem como premissa a inclusão efetiva dos alunos, quaisquer que sejam as etapas ou modalidades em que se situem, e ainda as suas limitações. Propiciando um convívio entre todos, no sentido de corroborar com a minimização dos preconceitos e favorecendo a redução dos tipos de exclusão que ainda existem no ambiente escolar. Essa, contudo, não é uma tarefa fácil. Mas visa contribuir para que possamos alçar uma realidade de equidade social.

A educação inclusiva pode ser definida com práticas de acolhimento ao indivíduo, respeitando as suas dificuldades e os direitos que the são assegurados perante as leis e os direitos que são inerentes como pessoas humanas.

A educação especial é uma modalidade de ensino que perpassa todos os níveis, etapas e modalidades, realiza o atendimento educacional especializado, disponibiliza os serviços e recursos próprios desse atendimento e orienta os alunos e seus professores quanto a sua utilização nas turmas comuns do ensino regular (BRASIL; SEESP, 2008, p. 16).

Pensar na educação inclusiva é pensar no poder da educação de transformar a sala de aula num ambiente acolhedor que o aluno possa ter autonomia no seu aprendizado, independentemente de possuir algum tipo de deficiência. Para tanto, o professor precisa estar preparado para lidar com diferentes situações e proporcionar tal fato. 


\section{- Reflexões da prática docente}

Percebe-se durante a formação de professores ocorre uma certa dificuldade por parte dos alunos em lidar com a realidade da sala de aula e com a complexidade dos saberes que servirão de base ao ofício docente.

[...] o saber docente não é uma coisa que flutua no espaço: o saber dos professores é o saber deles e está relacionado com a pessoa e a identidade deles, com a sua experiência de vida e com sua história profissional, com as suas relações com os alunos em sala de aula e com os outros atores escolares na escola, etc. (TARDIF, 2002, p. 11).

É a partir da prática que os licenciados poderão, diante do novo, revisar e agregar outros sentidos aos aprendidos na teoria, sendo esta ação chamada "orquestração dos saberes". Nesse sentido, observa-se que o período de formação, é um momento marcante e que permanecerá durante a realização do trabalho profissional.

Desse modo, os conhecimentos teóricos, práticos ou teórico-prático adquirido no decorrer desse processo de formação influenciará diretamente na realidade profissional de cada indivíduo formado, fazendo com que seja construída uma identidade profissional própria. E, dentre as diferentes profissionais inseridos no campo de formação, se encontra o pedagogo, que também tem como função em seu currículo à docência, que é necessariamente importante na formação da sociedade, pois esta encontra-se em direta relação com a educação.

Em relação à pedagogia, existem alguns conceitos essenciais para a compreensão do curso de pedagogia, sendo: ensino, a gestão e a pesquisa científica. Durante o percurso acadêmico, o futuro profissional da educação é hábil para desenvolver essas três habilidades, ou seja, ele pode escolher por uma delas para se aprofundar melhor na ocupação que futuramente escolher.

Libâneo (2001) descreve que:

Pedagogo é o profissional que atua em várias instâncias da prática educativa, direta ou indiretamente ligadas à organização e aos processos de transmissão e assimilação ativa de saberes e modos de ação, tendo em vista, objetivos de formação humana definidos em sua contextualização história. (LIBÂNEO, 2001a, p.44). 


\subsection{Formação de professores e a educação inclusiva}

A formação de professores é um tema que tem ocupado um espaço significativo na produção científica da área da Educação (OLIVEIRA, 2018). Segundo a mesma autora, o estudo de estratégias de formação que possam contribuir com o pensar do professor, seja da educação especial ou comum, vem sendo parte no decorrer de toda nossa trajetória acadêmica.

Entretanto, sabe-se que não é fácil ensinar a todos conjuntamente e, principalmente sabendo da complexidade de uma ação educativa, pois cada aluno precisa de uma atenção e um cuidado especial e diferencial, o professor precisa de ferramentas que permitam sua ação conjunta, e ainda assim observar a individualidade dos alunos.

Tavares, Santos e Freitas (2016) destacam em seu trabalho que a formação de professores é um assunto atualíssimo e tem sido motivo de preocupação entre acadêmicos que pesquisam a educação inclusiva, além de ser alvo de várias políticas públicas. A Política Nacional de Educação Especial na Perspectiva da Educação Inclusiva orienta os sistemas de ensino no sentido da promoção de respostas às necessidades educacionais especiais, garantindo "[...] formação de professores para o atendimento educacional especializado e demais profissionais da educação para a inclusão escolar" (BRASIL, 2007, p. $5)$.

No que se refere aos problemas relacionados à formação do professor, Pedroza (2014) aponta uma postura diferenciada do professor como sendo uma escola que visa à transformação do ser. Rosin-Pinola e Del Prete (2014) trazem as habilidades sociais do professor como forma de contribuição no processo de ensino-aprendizagem do aluno. As autoras afirmam que há necessidade de mudança nas práticas do professor, atentando para o aprimoramento da qualidade da relação educativa, principalmente quando se trata da educação inclusiva. Estas ainda trazem à tona a necessidade de refletir a prática do professor e repensar a ação educativa. Os professores, por sua vez, das salas especiais que devem ter uma formação mais especializada e os da classe comum devem avançar para um formato colaborativo de ensino, 
denominado coensino (ROSIN-PINOLA; DEL PRETE, 2014; VILARONGA; MENDES, 2014). Também pesquisas que indicam estratégias inclusivas e os saberes necessários à formação de professores para a inclusão têm sido desenvolvidas no Brasil (PIMENTEL, 2012; BENITEZ; DOMENICONI, 2014).

A importância do papel da universidade na formação de profissionais habilitados é defendida por Glat e Pletsch (2010). É necessário ter um ensino preparatório em busca de lidar melhor com determinadas situações em sala de aula e principalmente entender que cada aluno possui sua individualidade, para tanto é necessário preparo, embora muitos outros problemas estejam envolvidos em tal ensino, tal como: falta de investimento, infraestrutura, e um ensino coletivo de todos que compõe o ambiente escolar.

\subsection{Educação inclusiva, o que estabelece a Lei?}

No intuito de compreender um pouco o cenário da inclusão do Brasil, podemos destacar a Lei de Diretrizes e Bases da Educação Nacional (LBD) de 1961 como documento que possibilita expressar um olhar sobre a preocupação com a educação das pessoas com deficiência. "A preocupação de forma abrangente do Brasil com a Educação Especial ocorreu apenas em 1961, com a Lei de Diretrizes e Bases da Educação - LDB (Lei 4,024/61)." (LEIJOTO; KASSAR, 2009, p 28), até essas datas havia campanhas como a de Campanha nacional de surdo Brasileiro (CESB), Campanha Nacional de Educação e Reabilitação dos deficientes visuais (CNERDV) e em 1958, o Ministério da Educação e Cultura (MEC) já tinha funções de promover em todo território nacional, vários treinamentos de reabilitação e assistência educacional ás pessoas com deficiência; também com ajuda financeira para escolas públicas e privadas.

Podemos observar que depois dos anos 1960 é que irá de fato ocorrer à preocupação dos poderes públicos para com a inclusão escolar propriamente dita. Entretanto, há limites interpostos no teor da lei, no que tange a inclusão na rede regular. A LDB 4.024/61 vai tratar da Educação especial em dois artigos. 
$\mathrm{O}$ art. 88, que propõe o atendimento a pessoa com deficiência, embora aceite a "possibilidade" ou não de sua inserção na educação regular, admitindo que o processo educativo ocorra no sentido de promover uma "integração" com a comunidade.

Já o art. 89, que garante o apoio financeiro às instituições de caráter privado, que forem consideradas "eficientes" pelo CNE, representa a forma pela qual o Estado não se compromete e se responsabiliza para garantir esse apoio financeiro (KASSAR, 2009, p.210).

A Lei ainda aborda esse tipo de educação como "educação dos excepcionais" linguagem usual à época e que demonstra um tipo de concepção que subjaz a compreensão desses sujeitos, marcados pela diferença, excepcionalidade. Longe dos padrões considerados normais. Dessa maneira, o texto da LDB 4.024/61 anuncia:

Art. 88. A educação de excepcionais deve no que for possível, enquadrar-se no sistema geral de educação, a fim de integrá-los na comunidade. Art. 89. Toda iniciativa privada considerada eficiente pelos conselhos estaduais de educação, e relativa à educação de excepcionais, receberá dos poderes públicos tratamento especial mediante bolsas de estudo, empréstimos e subvenções (BRASIL, 1961, p. 01).

Nos 1970 a educação passa a ser vista como um progresso necessário da sociedade brasileira, e no ano de 1988 foi aprovado o Estatuto da infância e adolescência (ECA) ou lei 8.069/90, que vem substituir o código de menores, garantindo proteção e direito às crianças e aos adolescentes. Em seguida em, 1996 o acesso ao ensino fundamental é garantido como direito público e especificamente quanto ao atendimento das pessoas com deficiência, de acordo com a Lei $9.394 / 96$ que propõe o atendimento educacional especializado gratuito aos educandos com necessidades especiais, preferencialmente na rede regular de ensino (art. $4^{\circ}$, III). A partir daí então, surge a perspectiva da inclusão escolar para todos. 
Por tudo isso, a inclusão implica uma mudança de perspectiva educacional, porque não atinge apenas os alunos com deficiência e os que apresentam dificuldades de aprender, mas todos os demais, para que obtenham sucesso na corrente educativa geral (MANTOAN, 2006, p. 19).

Mas sabemos que $\mathrm{o}$ atendimento a essa modalidade nos dias atuais ainda se materializa com precariedade, e ainda vale ressaltar que muitos dos professores têm uma prática pedagógica e didática insegura no que tange ao desenvolvimento das atividades escolares junto às pessoas com deficiência, e muitas vezes não se sentem preparados para contribuir de maneira significativa com a aprendizagem destes alunos.

\subsection{Educação inclusiva, uma questão multidisciplinar}

Os professores devem buscar novas aprendizagens, sabendo diferenciar o ensino regular, para uma perspectiva mais significativa em relação ao ensino das pessoas com deficiência, "O outro é sempre e implacavelmente diferente, pois a diferença é o que existe, a igualdade é inventada e a valorização das diferenças impulsiona o progresso educacional" (MANTOAN, 2003, p. 28). Com o passar das décadas se consolidaram as premissas legais para que a proposta da inclusão pudesse caminhar para a efetividade, no entanto, ainda percebemos as dificuldades encontradas no sentido de concretizar essa proposta nas práticas.

Para Vitaliano (2007), a formação acadêmica dos professores universitários deve ser pensada de modo a contribuir para que desenvolvam uma prática pedagógica mais reflexiva e comprometida, ética e politicamente dentro das exigências do contexto atual. Para isso, os professores necessitam de preparo que vai além do conhecimento científico, visto que, no ambiente acadêmico, assim como em qualquer outro, há singularidades e conflitos de valores. Sant'Ana (2005) também aborda essa questão. Segundo a autora, a ausência de formação especializada para todos os educadores que trabalham com esse público constitui um sério problema na implantação das políticas de educação inclusiva. A autora destaca que os cursos de formação docente têm 
enfatizado aspectos teóricos, distantes da prática pedagógica, não preparando os profissionais para lidar com a diversidade dos educandos.

No entanto, para lidar com a questão de educação inclusiva, tem-se a necessidade de uma união dentro do âmbito escolar de todos aqueles componentes, tendo em vista que tanto o aluno, quanto o professor vai precisar de apoio para oferecer sempre o melhor possível de acordo com a necessidade de cada um, neste caso, há uma grande necessidade de preparo, tanto por parte do professor, quanto dos gestores, diretores, e todos aqueles que fazem que estão diretamente ligados ao ambiente da escola.

\subsection{Dados da literatura}

Para visualizar o cenário que envolve a temática foi feito um levantamento bibliográfico, no qual consistiu em quatro etapas.

A primeira foi a de busca e seleção de trabalhos que retratam sobre o tema proposta, depois deselecionados, a segunda etapa é o estabelecimento de critérios para inclusão e exclusão dos trabalhos, nos quais prioriza-se aqui aqueles que foquem no tema de educação inclusiva interligado a formação de professores.

$\mathrm{Na}$ terceira etapa é realizada a definição das informações a serem extraídas dos estudos selecionados categorização dos estudos, e na quarta etapa tem-se a interpretação dos resultados obtidos a partir da busca nas bases de dados.

Os artigos selecionados foram incluídos a partir de base de dados dos últimos 5 anos, sendo estes selecionados a partir de palavras chave tais como: "formação de professores"; "educação especial"; "educação inclusiva" e "carreira docente e educação inclusiva". Após a exclusão e seleção de artigos, diante dos critérios de inclusão pré-estabelecidos, tais trabalhos foram organizados em um quadro que demostra alguns detalhes sobre os arquivos selecionados 
A seguir o (Quadro 1) apresenta os artigos que foram selecionados, estes dispostos de acordo com os autores e bases científicas, com um total de 6 artigos.

Quadro 1:Análise de artigos, de acordo com os autores e bases cientificas

\begin{tabular}{|c|c|c|c|c|}
\hline ANO & TITULO & AUTORES & BASE & OBJETIVOS \\
\hline 2020 & $\begin{array}{ll}\text { A FORMAÇÃO } & \text { DE } \\
\text { PROFESSORES } & \\
\text { PARA A } & \\
\text { EDUCAÇÃO } & \\
\text { INCLUSIVA } & \text { DE } \\
\text { ALUNOS COM } & \\
\text { DEFICIENNCIASA } & \\
\text { PARTIR } & \text { DA } \\
\text { LITERATURA } & \end{array}$ & FELICETTI & $\begin{array}{c}\text { REVISTA } \\
\text { BRASILEIRA } \\
\text { SOBRE } \\
\text { FORMAÇÃO DE } \\
\text { PROFESSORES }\end{array}$ & $\begin{array}{l}\text { Objetivo principal foi } \\
\text { compreender com base na } \\
\text { literatura, como está sendo } \\
\text { discutida a formação dos } \\
\text { referidos professores } \\
\text { dentro da temática }\end{array}$ \\
\hline 2019 & $\begin{array}{l}\text { POLÍTICAS } \\
\text { PÚBLICAS } \\
\text { EDUCACIONAIS E } \\
\text { FORMAÇÃO DE } \\
\text { PROFESSORES: } \\
\text { CONVERGÊNCIAS E } \\
\text { DISTANCIAMENTOS } \\
\text { NA ÁREA DE } \\
\text { EDUCACCÃO } \\
\text { ESPECIAL }\end{array}$ & CARMO & $\begin{array}{l}\text { REVISTA } \\
\text { EDUCAÇÃO } \\
\text { ESPECIAL }\end{array}$ & $\begin{array}{l}\text { Objetivo do presente artigo } \\
\text { é analisar as políticas } \\
\text { públicas educacionais e as } \\
\text { de formação de } \\
\text { professores no intuito de } \\
\text { refletir sobre possíveis } \\
\text { convergências e } \\
\text { distanciamentos na } \\
\text { construção de um sistema } \\
\text { de ensino capaz de atender } \\
\text { à diversidade trazida pela } \\
\text { inclusão escolar. }\end{array}$ \\
\hline 2018 & $\begin{array}{c}\text { ENCONTRO ENTRE } \\
\text { EDUCAÇÃO } \\
\text { ESPECIALE } \\
\text { EDUCAÇÃO } \\
\text { INCLUSIVA: A } \\
\text { FORMAÇÃO DE } \\
\text { PROFESSORES- } \\
\text { MEDIADORES NA } \\
\text { ÁREA DA } \\
\text { DEFICIÊNCIA } \\
\text { INTELECTUAL }\end{array}$ & OLIVEIRA & $\begin{array}{l}\text { EDUCAÇÃO } \\
\text { UNISINOS }\end{array}$ & $\begin{array}{l}\text { O objetivo deste estudo foi } \\
\text { o de capacitar professores } \\
\text { especialistas da Rede } \\
\text { Municipal de Educação de } \\
\text { São Paulo, por meio de } \\
\text { uma estratégia piramidal, } \\
\text { para atuarem como } \\
\text { mediadores nas escolas } \\
\text { com os seus pares. }\end{array}$ \\
\hline
\end{tabular}




\begin{tabular}{|c|c|c|c|c|}
\hline 2017 & $\begin{array}{l}\text { A FORMAÇÃO DOS } \\
\text { PROFESSORES } \\
\text { PARA A EDUCAÇÃO } \\
\text { INCLUSIVA }\end{array}$ & $\begin{array}{l}\text { ALVES E } \\
\text { OLIVEIRA }\end{array}$ & $\begin{array}{l}\text { REVISTA DE PÓS- } \\
\text { GRADUAÇÃO } \\
\text { MULTIDISCIPLINAR }\end{array}$ & $\begin{array}{l}\text { O artigo tem como objetivo } \\
\text { mostrar a importância da } \\
\text { formação do professor para } \\
\text { a educação inclusiva, e } \\
\text { discutir o preparo destes } \\
\text { profissionais visando o } \\
\text { desenvolvimento de um } \\
\text { trabalho efetivo com casos } \\
\text { mais específicos dentro do } \\
\text { contexto educacional. }\end{array}$ \\
\hline 2016 & $\begin{array}{l}\text { A FORMAÇÃO DE } \\
\text { PROFESSORES } \\
\text { PARA A EDUCAÇÃO } \\
\text { INCLUSIVA: UM } \\
\text { OLHAR CRÍTICO }\end{array}$ & $\begin{array}{l}\text { SANTOS E } \\
\text { ARAUJO }\end{array}$ & $\begin{array}{c}\text { INTERFACES DA } \\
\text { EDUCAÇÃO }\end{array}$ & $\begin{array}{c}\text { Discute a formação inicial } \\
\text { dos docentes que atuarão } \\
\text { nos anos iniciais do ensino } \\
\text { fundamental. Tem como } \\
\text { objetivo geral analisar, no } \\
\text { que tange à educação } \\
\text { inclusiva, a estrutura do } \\
\text { curso de Pedagogia. }\end{array}$ \\
\hline
\end{tabular}

A autora Felicettl (2020), Diz que a inclusão social pressupõe que as diferentes identidades de uma cultura e o potencial dos indivíduos em sua singularidade, sejam reconhecidas e valorizadas, respeitando-se seus diretos e deveres (ESCUDERO; MARTÍNEZ, 2011). Todos eles têm direito de serem incluídos na sociedade e dela usufruírem, independentes da sua raça, religião, condição financeira, grau de instrução ou condição física e mental. As pessoas com deficiências fazem parte desse grupo com direito a inclusão.

Fazendo um recorte do público-alvo da inclusão, estão as pessoas com deficiências, são compreendidas como aquelas que têm impedimentos de caráter físico, mental, intelectual e sensorial, que, quando interagem com barreiras econômicas, culturais, tecnológicas, políticas, arquitetônicas, comunicacionais, são prejudicadas, podendo até ser discriminadas e excluídas da participação ativa em sociedade. Muitas vezes, elas são alvos de atitudes discriminatórias com a intenção de excluir, diferenciar ou restringir seus direitos (FONSECA, 2012).

Para Carmo (2019), diz que a política pública não é das tarefas mais fáceis, tamanha a variedade de conceitos que se encontra na literatura. Porém, 
as políticas públicas constituem um conjunto de atividades dos governos que influenciam direta ou indiretamente a vida das pessoas sobre sua governança.

Os modelos de formação dos profissionais do magistério, assumidos até o momento, visando qualificar para o trabalho no novo cenário da educação brasileira, parecem perpetuar o conhecimento hegemônico na Educação Especial, o qual está vinculado à carência de debate pedagógico e de discussões sobre o trabalho do professor (GARCIA, 2013).

Diversos pesquisadores da área de Educação Especial vêm apontando barras que dificultam o trabalho docente nas instituições de ensino, que vão desde a carência de condições apropriadas de trabalho aos problemas de ordem mais geral, como no campo da cultura e de conhecimentos específicos do processo de ensino-aprendizagem.

O estudo de Oliveira (2018) apresenta uma vivência a partir de uma capacitação com 220 professores vinculados aos Serviços de Educação Especial, os mesmos eram responsáveis pela capacitação dos professores das suas escolas, por meio de planejamentos estratégicos de formação piramidal nas 13 Diretorias Regionais de São Paulo.

A estratégia se mostrou positiva, no entanto, a autora ressalta, que ao considerar a proposta inclusiva e sua decorrência, a formação de professores em educação inclusiva é um tema urgente e absolutamente necessário, uma vez, que ninguém faz o que não sabe, cabendo as secretárias de educação ou sistemas de ensino buscar alternativas para ensinar outras metodologias escolares, impulsionadoras da aprendizagem na perspectiva da diversidade.

Alves e Oliveira (2017) relatam em seu trabalho que por lei as pessoas com deficiência têm direito ao acesso às classes comuns, e com essa obrigatoriedade, segundo estes mesmos autores, há um aumento deste público nas escolas, o que demanda investimentos para assegurar aprendizagem e desenvolvimento efetivo. Entretanto, eles destacam o fato de que muitos professores ainda estão pouco familiarizados com a teoria e a prática sobre o assunto, sendo necessário identificar o seu perfil acadêmico e suas experiências diante das necessidades educacionais, a partir disso, projetar 
formas de conhecimento que melhor se adequem a sua formação, necessidades e expectativas (ALVES; OLIVEIRA, 2017).

Sendo assim, é válido destacar que é necessário além do preparo, ter sempre uma formação continuada na área, junto a uma mente aberta, que esteja atenta a forma como conduzir determinadas situações, bem como está pronto para oferecer o auxílio necessário para o desenvolvimento do aluno.

O estudo de Noze e Vitaliano (2017) evidencia, que os professores apresentam saberes atitudinais que favorece a inclusão escolar com necessidades educacionais especiais (NEE) e para que se comprometa com a aprendizagem e desenvolvimentos desses estudantes, o professor deve ter empatia, buscando sempre uma formação e apoio colaborativo dos demais colegas de trabalho, para que possa refletir sobre os seus conceitos e esforçarse para ressignificá-los, assim melhorando o seu trabalho pedagógico.

Para isso, o professor deve ter uma formação adequada, experiências inclusivas positivas, o que irá fazer com que os professores se sintam mais seguros e capacitados para ensinar aos alunos com predisposto a desenvolver os saberes atitudinais recomendados para a inclusão (NOZE; VITALIANO, 2017).

A pesquisa de Santos e Araújo (2016) evidenciam que a formação de professores e a organização da grade curricular do curso de Pedagogia, em relação à educação inclusiva, têm fundamental ligação e importância no atendimento das pessoas com necessidades educativas especiais. Eles ainda defendem que a Pedagogia Histórico-Crítica e a Psicologia Histórico-cultural contribuem a respeito da formação de professores já que os profissionais da educação têm papel importante no desenvolvimento da aprendizagem do sujeito.

\subsection{A pedagogia e a educação inclusiva}

Devido a Faculdade Nacional de Filosofia da Universidade do Brasil, o curso de Pedagogia foi regulamentado no dia 4 de abril de 1939, pelo decretolei 1.190 (SILVA, 2003, p. 11); estando voltado à formação de bacharéis e 
licenciados para atuar em áreas distintas. O curso tornou-se indefinido até 1962 onde apresentou diretrizes mais definidas.

O curso de pedagogia abrange não só o magistério, porém a gestação escolar, assim como produção de conhecimento. De acordo com o parecer CNE/CP $\mathrm{n}^{\circ} 5$, de 13 de dezembro de 2005, que traz o perfil do graduado em pedagogia, este, por sua vez abrange, docência, gestão educacional, como também a elaboração e combinação do conhecimento científico e tecnológico do campo educacional.

Os anos de 1980 foram fundamentais para a busca da identidade do curso de pedagogia. Sobre isso escreveu Marques (1992, p. 71):

Os anos de 1980, geralmente considerados como a década perdida, não o foram, certamente, para a educação, se levarmos em conta o surgimento dos movimentos de educadores que desde então se reestruturam no país e, em especial, a atenção a esta questão relevante, que é a da formação do profissional da educação.

Durante esse período várias entidades foram formadas com o objetivo de determinar o estatuto epistemológico do curso de pedagogia, especialmente a CONARCFE (Comissão Nacional de Reformulação dos Cursos de Formação de Educadores - 1983) que deu origem, em 1994, à ANFOPE (Associação Nacional de Formação dos Profissionais da Educação). Esta Associação promoveu estudos e discussões que se operacionalizaram em pareceres do Conselho Nacional de Educação sobre as diretrizes do curso de pedagogia, instituídas em 2006.

\subsection{0 papel do professor no processo de aprendizagem}

Segundo Ferreira (2020), Diz que a colocação Professor surgiu no Brasil com um decreto de Dom Pedro I, em 15 de Outubro de 1827, onde determinava que todas as cidades, vilas e vilarejos tivessem suas primeiras escolas, no entanto o acesso a educação naquela época ainda era muito precário, onde só quem tinha condições de contratar professores eram as famílias mais ricas, nessa época, esses profissionais atuavam em escolas 
privadas ou vendiam seus conhecimentos a essas famílias. No entanto a partir da década de 30 , é que foi surgindo os grupos escolares onde o poder público se responsabilizou pela educação das crianças e com tudo houve a expansão dos grupos e a primeira escola de formação superior.

A partir da década de 1960 é que as mulheres chegaram às escolas nas condições de estudante, e depois de muitas conquistas nas condições de docente. Diante de tais necessidades especiais educacionais, o papel do professor é de suma importância na educação inclusiva, visto que o professor é a autoridade competente, direciona o processo pedagógico, interfere e cria condições necessárias à apropriação do conhecimento, é nessa perspectiva de estar aberto a conhecer o outro Freire afirma que:

O ideal é que na experiência educativa, educandos, educadoras e educadores, juntos 'convivam' de tal maneira com os saberes que eles vão virando sabedoria. Algo que não é estranho a educadores e educadoras. (FREIRE, 2005, p. 58) Normal. (BRASIL, 2006).

Sendo assim, cabe aos professores procurar novas posturas e habilidades que permitam problematizar, compreender e intervir nas diferentes situações que se deparam, além de auxiliarem na construção de uma proposta inclusiva, fazendo com que haja mudanças significativas pautadas nas possibilidades e com uma visão positiva das pessoas com necessidades especiais.

Por isso a importância do papel docente na percepção do aluno, no acompanhamento do mesmo em sala de aula e na busca constante de aprender e melhorar a si mesmo em sua prática atualmente, para construir uma escola que atenda adequadamente a alunos com características, potencialidades e ritmos diferentes de aprendizagem, não basta apenas que tenham professores e demais profissionais que uma escola normal apresenta.

Faz-se necessário que os profissionais e principalmente os professores, estejam capacitados para exercer essa função, atendendo a real necessidade de cada educando. Frente a isso, a Lei de Diretrizes e Bases da Educação Nacional - Lei nº 9.394/1996, artigo 62, situa:

A formação de docentes para atuar na educação básica far-se-á em nível 
superior, em curso de licenciatura, de graduação plena, em universidades e institutos superiores de educação, admitida, como formação mínima para o exercício do magistério na educação infantil e nas quatro primeiras séries do ensino fundamental, a oferecida em nível médio, na modalidade.

\section{CONSIDERAÇÕES FINAIS}

Com base nos dados descritos nesta dissertação, observa-se que mesmo com as dificuldades apresentadas na implementação da educação inclusiva, no ambiente universitário, os graduandos possuem ciência a respeito da temática, tanto através da disciplina, (currículo escolar), dentre outras, assim asseguram a importância do tema para sociedade no geral.

Contudo, é notório que existe uma longa jornada a ser trilhada no tratante a metodologia, didática, currículo e a formação dos docentes que contemplam a dificuldade da inclusão nas instituições de ensino regulares já que não é uma tarefa fácil. É sabido que a competência educacional do professor pode ser interessante para que haja maior entendimento e sensibilização na área da educação inclusiva, está troca de saberes, impulsiona o ensino-aprendizagem na perspectiva da diversidade.

Porém, o que se constata nas universidades é baixo investimento na formação de professores para atender a Educação Básica e um descompasso entre a reforma que proporcionou o acesso dos alunos e a preocupação em qualificar os docentes para o trabalho com os mesmos.

Todo esse cenário ocasiona, concomitantemente, transformações no trabalho docente e na formação que qualificassem o professores para lidar com essa nova realidade e garantir a qualidade do processo de ensino aprendizagem dos alunos com necessidades especiais.

Sendo assim, reforça a ideia de investimentos no ensino, não apenas como instrumento de suporte e capacitação aos professores regulares, mas também como agente de "internalização" nas escolas da política de inclusão de pessoas com necessidades especiais. 


\section{REFERÊNCIAS}

ALVES, A. R.; DE OLIVEIRA, A. S. A formação dos professores para a educação inclusiva. Revista de Pós-Graduação Multidisciplinar, v. 1, n. 2, p. 269-280, 2017.

ARANHA, M.S.F. Projeto Escola Viva garantindo o acesso e permanência de todos os alunos na escola: Alunos com necessidades educacionais especiais/ Adaptações Curriculares de Grande Porte. Brasília: MEC/SEE, 2000 a.

ARANHA, M.S.F. Projeto Escola Viva garantindo o acesso e permanência de todos os alunos na escola: Alunos com necessidades educacionais especiais/ Adaptações Curriculares de Pequeno Porte. Brasília: MEC/SEE, $2000 \mathrm{~b}$.

ARAÚJO, O. H. A.; MORAES, C. S. Formação docente, pedagogia e didática: temas que se entrecruzam? IN: 10 Encontro Internacional de Formação de professores, $\quad \mathrm{v} . \quad 10, \quad \mathrm{n} . \quad 1, \quad 2017 . \quad$ Disponível em:<https://eventos.set.edu.br/index.php/enfope/article/view/4557/1655>

Acesso em 12 de janeiro de 2019.

BENITEZ, P.; DOMENICONI, C. Capacitação de agentes educacionais: proposta de desenvolvimento de estratégias inclusivas. Revista Brasileira Educação Especial, v.20, n.3, p.371-386, 2014.

BEYER, H. O. Da Integração Escolar a Educação Inclusiva: implicações pedagógicas. IN: BAPTISTA, C. R. Inclusão e escolarização: múltiplas perspectivas. Porto Alegre. Mediação, p. 73- 81, 2006.

BLACK-HAWKINGS, K.The framework for participation: a research tool for exploringtherelationshipbetweenachievementandinclusion in schools. Derecho y Humanidades, v. 21, p. 85-110, 2013.

BRASIL. 1996. Congresso Nacional. Lei n. 9.394, de 20 de dezembro de 1996. Estabelece as Diretrizes e Bases da EducaçãoNacional. Diário Oficial da União n. 248,de 23/12/96. Brasília, Seção I, p. 27833.

BRASIL. Constituição 1988. Constituição; República Federativa do Brasil. Brasília: Senado Federal; 1988.

BRASIL. Decreto-lei $n^{\circ} 1.190$, de 4 de abril de 1939. Dá organização à Faculdade Nacional de Filosofia. Disponível em <www.senado.gov.br> Acesso em 12de janeiro de 2019.

MEC. Parecer CNE/CP no 03, de 21 de fevereiro de 2006. Reexame do Parecer CNE/CP n $5 / 2005$, que trata das Diretrizes Curriculares Nacionais para 0 Curso de Pedagogia. Disponível em <http://portal.mec.gov.br/cne/arquivos/pdf/pcp003_06.pdf>. Acesso em 12 de janeiro de 2019. 
BRASIL. Lei de Diretrizes e Bases da Educação Nacional. Lei 9.394, de 20 de dezembro de 1996. Diário Oficial da União: Brasília, 1996.

BRASIL. Ministério da Educação. Conselho Nacional de Educação. Diretrizes Curriculares Nacionais para o Curso de Graduação em Pedagogia - Resolução CNE/CP N¹, de 15 de maio de 2006. Disponível em: <http://portal.mec.gov.br/ cne/arquivos/pdf/rcp01_06.pdf> Acesso em 12 de janeiro de 2019.

BRASIL. Ministério da Educação. Portaria ministerial n. 1.793, de 27 de dezembro de 1994. Brasília, DF, 1994a.

Secretaria de Educação Especial. Política Nacional de Educação Especial na Perspectiva da Educação Inclusiva. Brasília, DF, jan. 2008a. [Documento elaborado pelo Grupo de Trabalho nomeado pela portaria n. 555/2007, prorrogada pela portaria n. $948 / 2007$, entregue ao ministro da Educação em 7 de janeiro de 2008]. Disponível em: <http:// portal.mec.gov.br/arquivos/pdf/politicaeducespecial.pdf $>$ Acesso em 12 de janeiro de 2019.

BRASIL. Política nacional de educação especial na perspectiva da educação inclusiva. Ministério da Educação / SECADI. Documento elaborado pelo Grupo de Trabalho nomeado pela Portaria Ministerial $n^{\circ} 555$, de 5 de junho de 2007, prorrogada pela Portaria $n^{\circ}$ 948, de 09 de outubro de 2007. Brasília, DF.

BUENO, J. G. S. Educação Especial Brasileira: integração/segregação do aluno diferente. São Paulo: Educ, 1993.

CANDAU, VM. (Org.) A didática em questão. Petrópolis: Vozes, 1984.

CARVALHO, M. A. A. S.; SILVEIRA, S. P. M. F.; MARQUES, M. L.; ARNAUD, A. P. A. R. A formação de professores para educação inclusiva. IN:XII Congresso Nacional de Educação, 2017. Disponível em: <https://educere.bruc.com.br/arquivo/pdf2017/22981_11845.pdf> Acesso em 12 de janeiro de 2019.

CARVALHO, R. E. Educação Inclusiva: com os pingos nos is. 3. ed. Porto Alegre:Mediação, 2005.

CARVALHO, R. E. Removendo barreiras para a aprendizagem. 4. ed. Porto Alegre: Mediação, 2004.

CENSO DA EDUCAÇÃO SUPERIOR, 2018. Disponível em: $<$ http://download.inep.gov.br/educacao_superior/censo_superior/documentos/2 019/censo_da_educacao_superior_2018-notas_estatisticas.pdf> Acesso em 12 de janeiro de 2019 .

CENSO ESCOLAR DA EDUCAÇÃO BÁSICA, 2017. Disponível em: <http://www.deolhonosplanos.org.br/microdados-censo-escolar-2017/> Acesso em 12 de janeiro de 2019.

DAVID, N. A. N. A formação de professores para a educação básica: dilemas 
atuais para a educação física. Revista brasileira de ciências do esportev. 23, n. 2, p. 119 - 133, 2002.

DE VITTA, F.C.F.D.; DE VITTA, A.D; MONTEIRO, A.S. Percepção de professores de educação infantil sobre a inclusão da criança com deficiência. Revista Brasileira de Educação Especial, v.16, n.3, p.415-428, 2010.

DEIMLING, N. N. M. A Educação Especial nos cursos de Pedagogia: considerações sobre a formação de professores para a inclusão escolar. Educação Unisinos, v. 17, n. 3, p. 238-249, = 2013.

FERRARI, M. A. L. D.; SEKKEL, M. C. Educação Inclusiva no EnsinoSuperior: Um Novo Desafio. Psicologia ciência e profissão, v. 27, n. 4, p. 636-647, 2007.

FRANCO, M. A. S. Práticas pedagógicas de ensinar-aprender: por entre resistências e resignações. Educação e Pesquisa. 41, n. 3, p. 601-614, 2015.

FREIRE, P. Pedagogia da autonomia: saberes necessários a prática educativa. São Paulo: Paz eTerra, 1996.

GARCÍA, M. C. A formação de professores: centro de atenção e pedra-detoque. IN: NÓVOA, A. Os professores e a suaformação. 3. ed. Lisboa: Dom Quixote, p. 51-76, 1997.

GEUBERT, M. C. C. Inclusão: Uma realidade em Discussão. Curitiba: Editora Ibpex, $2^{\circ}$ Ed. 2007.

GILON, F. S.; CARDOSO, A. L. Um olhar sobre a formação em educação inclusiva na matriz curricular do curso de Licenciatura em Educação Física. Revista Digital. Año 19, n. 194, 2014.

GLAT, R.; PLETSCH, M. D. O papel da universidade no contexto da política de educação inclusiva: reflexões sobre a formação de recursos humanos e a produção de conhecimento. Revista Educação Especial, v.23, n.38, p.345356, 2010.

JOHNERM, L. E. A. Vivendo a diversidade da educação inclusiva nos dias atuais. IN: XV Seminário Internacional de Educação. Disponível em: $<$ https://www.feevale.br/Comum/midias/fb9deefe-d179-4f41-9e8bdb7c9760d5fb/Vivendo\%20a\%20diversidade\%20da\%20educa\%C3\%A7\%C3\% A3o\%20inclusiva\%20nos\%20dias\%20atuais.pdf> Acesso em 12 de janeiro de 2019.

KASSAR, M. C. M. A formação de professores para a educação inclusiva e os possíveis impactos na escolarização de alunos com deficiências. Cad. CEDES, Campinas, v. 34, n. 93, p. 207-224, 2014.

LEIJOTO, C. P.; KASSAR, M. C. M. A organização didática do professor do ensino fundamental do processo de inclusão. Relatório de Iniciação 
Científica. Programa Institucional de Iniciação Científica: PIBIC: Universidade Federal de Mato Grosso do Sul, Conselho Nacional de Desenvolvimento Científico e Tecnológico, 2009.

LIBÂNEO, J. C. P. Pedagogia e Pedagogos, para quê? $4^{a}$ Ed. São Paulo: Cortez, 2001.

LUZ, R. M. N.; SARTORI, J. S. Gestão escolar na perspectiva da educação inclusiva. Disponível em: <https://rd.uffs.edu.br/bitstream/prefix/2030/1/LUZ.pdf> Acessado em 12 de janeiro de 2019.

MANTOAN, M. T. A Integração de pessoas com deficiência: contribuições para uma reflexão sobre o tema. São Paulo: Memnon, 1997.

MANTOAN, M. T. É. Inclusão escolar: O que é? Por quê? Como se faz? São Paulo: Ed. Moderna, 2003.

MANTOAN, M. T. E. O Direito de Ser, Sendo Diferente, na Escola. In D. R. (Ed.). Inclusão e Educação: doze olhares sobre a educação inclusiva. São Paulo: Summus, p. 183-209, 2006.

MARINHO, I. P. C. Educação inclusiva do aluno com necessidades especiais: desafios e perspectivas para os gestores. Trabalho de Conclusão de Curso (Especialista em Psicomotricidade Clínica e Escolar) Departamento de Educação Física, Universidade Federal do Rio Grande do Norte, Natal, RN, 22 f., 2018.

MARQUES, M. O. A reconstrução dos cursos de formação do profissional da educação. Em Aberto, v. 12, n. 54, p. 43-50, 1992.

MENDES, M. P. Educação Inclusiva e a Declaração de Salamanca: consequências ao sistemaeducacional brasileiro. Revista Integração, a. 10, n. 22, 2012.

MICHELS, M. H.; LEHMKUH, M. S. A política de formação de professores do ensino fundamental para atender alunos da educação especial. Educação e Fronteiras On-Line, v.5, n.13, p.60-72, 2015.

NOZI, G. S.; VITALIANO, C. R. Saberes de professores propícios à inclusão dos alunos com necessidades educacionais especiais: condições para sua construção. Revista Educação Especial, v. 30, n. 59, p. 589-602, 2017.

OLIVEIRA, A. A. S. Encontro entre Educação Especial e Educação Inclusiva: a formação de professores-mediadores na área da deficiência intelectual. Educação Unisinos, v. 22, n. 2, p. 138-146, 2018.

OLIVEIRA, A. S.; ALVES, A. R. A formação dos professores para a educação inclusiva. Revista de Pós-graduação Multidisciplinar, v. 1, n. 2, p. 269-280, 2017. 